\title{
Newborn Stroke in Congo: First Case Report
}

\author{
Gaston Ekouya Bowassa ${ }^{1,2, *}$, Paul Macaire Ossou-Nguiet ${ }^{1}$, Aymar Pierre Gildas Oko1, \\ Annie Rachel Okoko ${ }^{1}$, Engoba Moyen ${ }^{1}$, Nelly Yvette Ngakegni ${ }^{2}$, Georges Marius Moyen ${ }^{1}$ \\ ${ }^{1}$ Faculty of Health Sciences, Marien NGOUABI University, Brazzaville, Congo \\ ${ }^{2}$ Unit of Neonatology, University Hospital of Brazzaville, Brazzaville, Congo
}

\section{Email address:}

ekouyabg@yahoo.fr (G. E. Bowassa)

\section{To cite this article:}

Gaston Ekouya Bowassa, Paul Macaire Ossou-Nguiet, Aymar Pierre Gildas Oko, Annie Rachel Okoko, Engoba Moyen, Nelly Yvette Ngakegni, Georges Marius Moyen. Newborn Stroke in Congo: First Case Report. American Journal of Psychiatry and Neuroscience. Special Issue: Clinical Neurosciences in Tropical Practice. Vol. 3, No. 5-1, 2015, pp. 22-24. doi: 10.11648/j.ajpn.s.2015030501.15

\begin{abstract}
Neonatal strokes are defined by the occurrence of any cerebrovascular event between the 20th week of gestation and 28th day after birth. It is an uncommon disease whose incidence varies according to the authors. The localized seizures are the main symptoms. But nonspecific symptoms like bradycardia, bradypnea and poor feeding may reveal the pathology. The diagnosis has been facilitated by the development of brain imaging techniques. It can be done during the acute phase or retrospectively by viewing sequelae's images. They are characterized by their etiology and therapeutic management that differ from those found in young adults. The prognosis is dominated by the occurrence of neurological sequelae such as epilepsy or motor deficits. We report a case of stroke in the neonatal period, observed on the sixteenth day of life.
\end{abstract}

Keywords: MRI, Newborn, Seizures, Stroke

\section{Introduction}

Neonatal strokes are defined by the occurrence of any cerebrovascular event between the twentieth week of gestation and twenty eight days after birth [1,2]. It is an uncommon disease. Its incidence varies according to the authors because of the difficulties associated with epidemiological data, and the mode of revelation [1]. The incidence is estimated to 1 in 4.000 live births in perinatal period, and 63 in 100.000 live births in neonatal period $[1,2]$. Diagnosis is made on the occasion of partial or localized seizures which it is responsible in 6.1 to $14 \%$ of cases in fullterm newborns $[3,4]$. The focal nature of signs and the context distinguish cerebral infarction to anoxic-ischemic encephalopathy [5]. As in adults, stroke may involve future motor and cognitive development in child $[1,6]$. Current definitions include data from magnetic resonance imaging (MRI), particularly positivity diffusion sequences, or atrophy and /or parenchymal destruction while an earlier imaging (ultrasound, CT or MRI without diffusion) does not show this atrophy. [7] These criteria make it difficult for the diagnosis of neonatal stroke in many African countries, where accessibility of newborns in MRI is not always possible. It is in this context of limited technical platform, we report a first case of a stroke in a newborn in the sixteenth day of life in Brazzaville.

\section{Observation}

The newborn K. G, female is admitted from home in the sixteenth day of life for seizures.

In medical history, the father is 48 years old, a professional pastry cook, he has no particular medical history. The mother is 40 years old, she is a dressmaker and has no particular medical history. K.G is third child. There were no notable incidents during the current pregnancy. The delivery was vaginally at term, with good adaptation to extra-uterine life. Birth weight was $3250 \mathrm{~g}$ for $49 \mathrm{~cm}$ of length and head circumference to $33 \mathrm{~cm}$. Clinical examination was normal. The output from maternity was authorized at the third day of life.

In the sixteenth day of life, the newborn has repeated partial seizures justifying the consultation of pediatric emergency (University Hospital of Brazzaville) by the parents and his admission to the neonatal unit.

On admission, there was repeated seizures, tonic-clonic located at the right side of the body with ocular revulsion. The clinical examination after seizures noted, weighing 3400 $\mathrm{g}$, size $49.5 \mathrm{~cm}$ and a head circumference of $33 \mathrm{~cm}$. There was an axial hypotonia, but the newborn consciousness was 
normal. The archaic reflexes were normal. The heart sounds were regular, at 130 beats per minute, capillary refill time of less than 3 seconds, and the femoral pulses were present. Respiratory frequency was 30 breaths per minute with free lung fields. The abdomen was soft on palpation, without palpable masses. The remainder of the physical examination was normal.

In biological assessment, blood sugar and serum calcium were normal. Serum electrolytes and creatinine were also normal. There were no inflammatory syndrome and lumbar puncture brought out a clear cerebrospinal fluid whose analysis was normal. The brain CT-scan showed hypodensity in left fronto-parietal area, evoking a stroke in the territory of the superficial middle cerebral artery (Figure 1), with contralateral border zone infarct. The hemostasis tests and echocardiography doppler were normal. He did not have an electroencephalogram.

The final diagnosis was stroke on the superficial middle cerebral arterial territory and border zone infarct of likely hemodynamic etiology.

Management consisted of the administration of phenobarbital with loading dose of $20 \mathrm{mg} / \mathrm{kg}$ follow by $5 \mathrm{mg}$ $/ \mathrm{kg}$ per day for 3 days. Intravenous hydration by $5 \%$ glucose serum with electrolytes, and enteral nutrition by feeding tube of mother's milk were administrated.

The outcome is marked by the cessation of seizures in the first day of hospitalization, a normal neurological examination on the third day of hospitalization. The output have been decided after 4 days of hospitalization with anticonvulsant treatment (sodium valproate). The child was seen in the first, third and ninth month, and the neurological examination is normal, but she has some partial seizures, confirmed by electroencephalography (EEG). The neurological monitoring is ongoing.

\section{Comments}

The stroke incidence has been increasing in recent years with the contribution of brain imaging. [1] This observation is the first in our country due to the recent opening of a modern brain imaging unit (CT-scan and MRI).

Seizures, localized to a part of body with or without secondary generalization are the main symptom and mode of revelation of stroke according to different authors $[1,2,6]$. They usually occur within the first 72 hours of life $[1,8]$. Consciousness post critical period is normal in rule [8]. There is no obvious hemiplegia due to the immaturity of the movement control by the motor cortex. Other events are less specific: bradycardia, bradypnea, hyporeactivity, poor food intake or cyanosis $[6,8]$. The diagnosis can be made retrospectively by occurred of neurodevelopmental disorder that leads to a brain imaging revealing sequelae aspect of perinatal stroke. [8]

The diagnosis is not easy in low-income countries such as Congo, where the technical equipment of health facilities is not always effective; but also the high costs of diagnostic examinations and medicines used in the management of patients, because of the lake of health care insurance system. According to Selton et al [3], the electroencephalogram (EEG) has an important diagnostic value, when critical neonatal events lead to its realization. The focused nature of EEG abnormalities has a good orientation value. For Mercuri et al [9], the background activities in EEG has also a predictive value of motor sequelae; however Sreenan et al [10], did not observed this findings. The simultaneous presence in his series of cases between stroke and hypoxicischemia could be in partly responsible for these differences [3].

Imaging particularly, the MRI, is the modality of choice for diagnosis. It allows the topographical lesion analysis, specifying its focal character, the extent of cerebral infarction, the vascular territory involved, and subsequently the severity of necrotic lesions [6-8]. Diffusion sequences allow highlighting cerebral infarction in the first minutes, by a hyper intense signal with lower diffusion coefficient [1]. Cerebral hemorrhage on T2 gradient spin echo sequences are displayed as a hypo intense signal [1]. In case of nonavailability of MRI, as in our case, the brain CT-scan can be performed in an emergency [1]. Although its technical conditions are easier, CT-scan can still be normal in the early hours of the development of ischemic stroke [1]. The transfontanellar ultrasound, usually available in the neonatology poorly equipped units, is easy to use in the newborn. It highlights hyper shine thalami which is specific for ischemic necrosis of this region [9]. It can however be very sensitive for the detection of very anterior or posterior abnormalities [11].

In our case, the stroke concerned the territory of the left middle cerebral artery territory. Mercuri and al. [9] also noted a predominance of involvement of the left MCA territory without an explanation of this phenomenon. BrasseurDaudruy and al. [2], in a series of 10 patients reported 8 cases of infarcts in middle cerebral arterial territory without preferential lateralization. For them, it is possible that the number of infarcts in anterior and posterior cerebral arteries is underestimated because of their tendency often asymptomatic [2].

Several etiological mechanisms of cerebral infarction of the newborn have been particularly identified: coagulation disorders in the mother, congenital heart diseases and severe sepsis complicated with disseminated intravascular coagulation [1,6]. However hemodynamic origin with junctional localization of lesions has never been reported. We did not, with regard to our observation, found a cause, but the topography of the lesions, by analogy in adults did evoke hemodynamic origin [12].

Child prognosis is very variable, with low mortality 2 to $3 \%$ [6]. Lynch and al in 2001 [13], in a series of 579 neonatal cerebral infarcts, noted $3 \%$ of deaths and $57 \%$ of neurological and cognitive sequelae disorders. According to Lee and al. [14], 81\% of children who have neonatal cerebral infarction had a neurological disorder after monitoring during one year. They have noted 39\% cases of epilepsy, $58 \%$ cases of motor deficits, and in $25 \%$ cases of acquisition delay 
of language and behavioral problems [14]. Selton and al. [3] in a smaller series of 10 children followed for 3-9 years, three patients has normal evolution and three children with sequelae such as epilepsy, frustrates monoparesis of the right leg and a case of right hemiparesis. The poor prognostic factors are marked by the late of revelation, large infarct size, involvement of the Broca's area, Wernicke, basal ganglia or the internal capsule, and abnormalities of the electroencephalogram background [6,14]. In our case, although the two prime factors of poor prognosis mentioned above have been found, and partial epilepsy was noted at nine months, we are not possible at the current time to establish a subsequent neurological prognosis of this child. Recovery mechanisms are complex, but unlike in older children or adults, the brain of the newborn is a very dynamic system, with an important part of synaptogenesis [15]. Some authors [16, 17] have reported the important role of cell proliferation and migration of the sub-ventricular zone. Some of these cells are multipotent and provide training for neuroblasts and glial cells [16].

\section{Conclusion}

This observation, first in our country of a stroke in neonatal period recalls that this age group is also affected by this disease. Convulsions, especially partial, are the quintessential mode of revelation. The development of imaging techniques is the cause of the increase in the number of identified cases. But nevertheless, they remain restricted use in our practice, as in most African countries. Collaboration between pediatricians, radiologists and neurologists is so essential to the management of the acute phase of stroke and its complications in the newborn.

\section{References}

[1] Béjot Y, Chantegret C, Osseby G-V, Chouchane M, Huet F, Moreau T, et al. Stroke in neonates and children. Rev Neurol $2009 ; 165: 889-900$.

[2] Brasseur-Daudruy M, Bordarier C, Cellier C, Eurin D, Marret $\mathrm{S}$, André C, et al. Stroke newborn term: RMI findings. J Radiol $2008 ; 89: 1085-93$.

[3] Selton D, André M, Hascoët JM. EEG and ischemic stroke in full-term newborns. Neurophysiol Clin $2003 ; 33: 120-9$.
[4] Nguyen The Tich S. Epileptic seizures in neonates : diagnosis and management. Med Therap Pediatr 2006 ; $9: 269-74$.

[5] Chabrier S, Husson B, Dinomais M, Landrieu P. Nguyen The Tich S. New insights (and new interrogations) in perinatalarterial stroke. Thromb Res $2011 ; 127: 13-22$.

[6] Chadie A, Conti C, Rondeau S, Marret S. Strokes newborn at term. Arch Pediatr 2012; 19: $96-7$.

[7] Chabrier S, Vuillerot C, Égo A, Debillon T. Arterial ischemic stroke occurring in the neonatal period (excluding preterm newborns): why do we need guidelines for clinical practice? Arch Pediatr 2014; 21: 934 - 7.

[8] Charollais A, Husson B, Dreyfus M, Landrieu P. Diagnostic investigations in stroke newborn. Med Therap Pediatr 2001; 4: $119-26$.

[9] Mercuri E, Rutherford M, Cowan F, Pennock J, Counsell S, Papadimitriou $M$, et al. Early prognostic indicators of outcome in infants with neonatal cerebral infarction: a clinical, electro-encephalogram and magnetic resonance imaging study. Pediatrics 1999; 103: $39-46$.

[10] Sreenan C, Bhargava R, Robertson CM. Cerebral infarction in the term newborn: clinical presentation and long-term outcome. J pediatr 2000; 137: $351-5$.

[11] Lemesle M, Manceau E, Osseby GV, Madinier-Chappart N, Moreau T, Giroud M. Ischemic cerebrosvasular stroke of arterial origin in the child. Rev Neurol 2001; 157: 1255 - 63 .

[12] Otiobanda GF, Ossou-Nguiet PM, Itoua C, Ndinga H, Chobli M. bilateral border zone infarct during spinal anaesthesia for caesarean section. Ann Fr Anesth Rea 2013; 32: 207 - 8 .

[13] Lynch JK, Nelson KB. Epidemiology of perinatal stroke. Curr Opin Pediatr 2001; 13: 499 - 595.

[14] Lee J, Croen LA, Lindan C, Nash KB, Yoshida CK, Ferriero $\mathrm{DM}$, et al. Predictors of outcome in perinatal arterial stroke: a population based study. Ann Neurol 2005; 58: $303-8$.

[15] Kirton A, Deveber G. Life after perinatal stroke. Stroke 2013; 44: $3265-71$.

[16] Young CC, Brooks KJ, Buchan AM, Szele FG. Cellular and molecular determinants of stroke-induced changes in subventricular zone cell migration. Antioxid Redox Signal 2011; 14: $1877-88$.

[17] Kratzer I, Chip S, Vexler ZS. Barrier mechanisms in neonatal stroke. Frontier in Neurosci 2014; 8: 359. 